\title{
Chronic inflammatory bowel disease in children: a complex problem in management
}

\author{
J A Walker-Smith
}

Children with chronic inflammatory bowel disease in the UK are still often cared for by general paediatricians with the assistance of adult gastroenterologists or surgeons. This is not the case in North America or much of Europe. Juvenile onset Crohn's disease is an increasing problem as a recent report from Scotland indicates. ${ }^{1}$ Both diagnosis and management are complex and the time has come for all children with these disorders to be at least reviewed in a tertiary centre for paediatric gastroenterology ${ }^{2}$ in order to improve the delivery of care.

There is clearly an important genetic aspect to inflammatory bowel disease. There is some evidence that genetic anticipation may occur to explain the tendency for children to be younger than their parents at diagnosis but some relate this to ascertainment. ${ }^{3}$

Delay in diagnosis is a common feature in these children. ${ }^{4}$ It is often considered that partial or inadequate diagnosis is enough. Children deserve the same comprehensive diagnostic approach as is available to adults in order to plan rational management. After all, these disorders are likely to be life long. When cared for initially by adult physicians or gastroenterologists, vital measurement of height and grading of puberty are often not done. Accurate diagnosis and effective treatment are both essential for ideal management. Smooth transfer to adult clinics in due course is essential.

University

Department of

Paediatric

Gastroenterology,

Royal Free and

University College

Medical School, Pond

Street, Hampstead, London NW3 2QG, UK

Correspondence to: Professor Walker-Smith

Submitted 6 September 1999

Accepted 16 November 1999

\section{Diagnostic criteria}

Until the 1970s Crohn's disease was thought to be uncommon in children, although ulcerative colitis had been recognised in children from the 1920s. The diagnosis of Crohn's disease is more difficult in children than in adults because systemic manifestations such as growth failure and delayed puberty may dominate the early clinical picture. As a result, diagnosis can be delayed. ${ }^{5}$ However, the modern approach of fibreoptic ileocolonoscopy with multiple mucosal biopsies, coupled with high quality barium studies adapted for children, has led to speedy and accurate diagnosis. ${ }^{6}$

Table 1 Relation between endoscopic diagnosis and routine laboratory tests in children with chronic gastrointestinal symptoms; values are \%

\begin{tabular}{lcllll}
\hline & $\begin{array}{l}\text { Crohn's } \\
\text { disease } \\
(n=26)\end{array}$ & $\begin{array}{l}\text { Ulcerative } \\
\text { colitis } \\
(n=13)\end{array}$ & $\begin{array}{l}\text { Polyps } \\
(n=8)\end{array}$ & $\begin{array}{l}\text { Normal } \\
(n=37)\end{array}$ & $\begin{array}{l}\text { Others* } \\
(n=7)\end{array}$ \\
\hline Investigation & 16 & 30 & 12 & 6 & 28 \\
$\begin{array}{l}\text { Erythrocyte sedimentation } \\
\text { rate }>25 \mathrm{~mm} / \text { hour }\end{array}$ & 85 & 23 & 0 & 0 & 42 \\
Albumin $<36 \mathrm{~g} / 1$ & 35 & 15 & 0 & 0 & 14 \\
Platelet count $>400 \times 10^{9} / 1$ & 88 & 70 & 12 & 6 & 42 \\
C reactive protein $>5 \mathrm{mg} / 1$ & 100 & 60 & 0 & 0 & 42 \\
All investigations normal & 0 & 8 & 88 & 91 & 28 \\
\hline
\end{tabular}

${ }^{\star}$ Others include tuberculosis, indeterminate colitis, and lymphoid nodular hyperplasia. From Beattie et al. ${ }^{19}$

\author{
Box 1: Differential diagnosis of \\ inflammatory bowel disease in \\ childhood inflamed colonic mucosa \\ - Inflammatory bowel disease \\ - Infective colitis \\ - Amoebic colitis \\ - Cows' milk or allergic colitis \\ - Autoimmune colitis \\ - Chronic granulomatous disease \\ - Immunodeficiency \\ - "Microscopic colitis" \\ - Behçet's disease \\ - Hirschsprung's enterocolitis \\ - Non-specific colitis with lymphoid \\ nodular hyperplasia \\ - Intractable enterocolitis of infancy \\ - Metabolic disorders
}

Three diagnostic categories of chronic inflammatory bowel disease may be recognised: Crohn's disease, ulcerative colitis, and indeterminate colitis. The latter is a term reserved for those children who have a definite histological diagnosis of colitis but in whom it is not possible, at least at first, to characterise the disorder as either Crohn's disease or ulcerative colitis.

The possible causes of an inflamed colonic mucosa in addition to inflammatory bowel disease are listed in box 1 . The relationship between endoscopic diagnosis and routine laboratory tests in children with chronic gastrointestinal symptoms is given in table 1 . This indicates the particular value of $\mathrm{C}$ reactive protein and platelet count when screening for inflammatory bowel disease.

\section{Crohn's disease}

DIAGNOSIS

A secure or definite diagnosis may be made on the basis of the following observations ${ }^{78}$ :

(1) The findings of characteristic histology with the non-caseating granulomata on endoscopic biopsy. ${ }^{89}$

(2) The presence of terminal ileal ulceration on endoscopy and histological ileitis with a characteristic radiological appearance. ${ }^{10}$

(3) The presence of characteristic histology after intestinal resection (non-caseating granulomas and fissuring ulceration). ${ }^{9}$

A probable or presumptive diagnosis may be made when radiological investigations show the typical abnormalities found in Crohn's disease in a child who has clinical features to suggest its presence. 
Histologically, Crohn's disease is probable if one or more of the following features are present:

(1) Focal inflammation

(2) Submucosal or transmural inflammation

(3) Lymphocyte aggregates (without germinal centres)

(4) Mucous retention in the presence of more than minimal inflammation.

GROWTH FAILURE

Impaired linear growth is very common in childhood and adolescent Crohn's disease. ${ }^{11} \mathrm{~A}$ detailed auxological study of height velocity in prepubertal boys with active Crohn's disease showed that of 36 patients, 20 were growing at less than 25 th centile velocity and 13 at less than 3 rd centile velocity. ${ }^{12}$

Kirschner and Sutton first reported the association of growth failure and low levels of somatomedin-C, that is, insulin-like growth factor (IGF-1) in young patients with Crohn's disease. ${ }^{13}$ They found a relationship between restoration of normal energy intake and increase in somatomedin- $C$ concentrations. Thomas et al reported low IGF-1 levels in active childhood Crohn's disease in association with normal levels of the growth hormone independent binding protein IGFBP-3. ${ }^{14}$ This is the principal carrier protein for IGF-1 in the circulation.

The origins of growth failure in Crohn's disease are still a matter of some debate. Kirschner et al drew attention to the frequency of nutritional deficiency in Crohn's disease, emphasising the nutritional consequences of intestinal inflammation upon growth. ${ }^{15}$ Subnormal values of mid-upper arm circumference, and mid-upper arm area are indeed found in children presenting with active Crohn's inflammation. ${ }^{16}$ A reduced energy intake in children with active Crohn's disease which improved with treatment (enteral nutrition or steroids) has also been shown. ${ }^{17}$

The principal influence upon linear growth in Crohn's disease is probably the presence of active inflammation. The association of raised serum concentrations of tumour necrosis factor- $\alpha$ and $C$ reactive protein with growth failure in children with Crohn's disease has been shown. ${ }^{18}$ Beattie et al showed a striking fall in serum $\mathrm{C}$ reactive protein associated only two weeks after the start of nutritional supplementation with significant increases of IGF-1 and IGFBP-3. ${ }^{19}$ This is strongly suggestive of a direct relationship between the inflammatory process and the regulation of these peptides. Interleukin- 6 can also cause impairment of linear growth in transgenic mice through a decrease in IGF- $1 .^{20}$

There is also evidence that a remission of Crohn's disease induced by enteral nutrition reduces mucosal cytokine production. ${ }^{21}$ Using reverse transcriptase polymerase chain reaction enteral feeding has been shown to significantly reduce interleukin-1 in ileal tissue. ${ }^{22}$

Intestinal resection of inflamed bowel causes less definite changes in IGF-1 and IGFBP-3 levels than does enteral feeding, although the improvement in $\mathrm{C}$ reactive protein was striking. ${ }^{19}$

UNUSUAL CLINICAL MANIFESTATIONS

Crohn's disease is often associated with skin manifestations such as erythema nodosum and even pyoderma gangrenosum. These nonspecific lesions are different from skin lesions which have the typical histology of Crohn's disease. Such lesions are divided into those that are contiguous with the gastrointestinal tractfor example, perianal or peristomal and those which are separated from the affected parts of the alimentary tract. These are sometimes called metastatic Crohn's disease. Such lesions with granulomas may occur in the genital area and may respond to metronidazole therapy. ${ }^{23}$

\section{MANAGEMENT}

Enteral nutrition is now the preferred primary therapy for Crohn's disease in childhood apart from those with very severe disease and also those with severe local perianal disease. ${ }^{24}$

Drug therapy and surgical treatment also continue to play a vital part but enteral feeding may now be recommended as the first line treatment for Crohn's disease in most cases. The evidence for success is strongest for small intestinal disease $\mathrm{e}^{25}$ but there is also evidence for improvement with colonic disease. ${ }^{26}$ The exceptions are very severe disease when intravenous hydrocortisone, intravenous antibiotics, and parenteral nutrition may be required and also there is little evidence that enteral feeding is effective for perineal disease.

Various enteral feedings have been usednamely, true elemental, semielemental, and polymeric diets. The latter has the great advantage that it is palatable and does not usually need to be given intragastrically as is the case with the other types of feeds.

In children it is recommended that the child has the enteral feeding as the sole nutrition for eight weeks with only additional water permitted. This is followed by a period of food reintroduction over a number of weeks. Should symptoms return with a particular food this should be temporarily withdrawn and a further attempt to reintroduce be made later on. In most cases after four months the child is back to a normal diet and in remission. The author now recommends Modulin IBD (Nestlé) developed as CT3211 as the ideal enteral feeding. It is a polymeric diet.

Remission should be assessed clinically and biochemically. The $\mathrm{C}$ reactive protein concentration (table 1) is the most useful laboratory parameter to follow. Unfortunately there is a $30 \%-50 \%$ relapse rate in the first year after enteral nutrition. However in most cases children respond to further enteral feeding.

The great advantage for children is the absence of steroid side effects when this approach is used. Indeed when drunk by mouth enteral nutrition is without any side effects. It also has a short term growth effect unlike steroids, which usually retard growth. It may be wise to add a 5-ASA drug such as mesalazine to treatment when there is colonic disease, although this is not yet evidence based. 
When a major relapse occurs oral steroids need to be given usually in a dose of $1 \mathrm{mg} / \mathrm{kg}$ of prednisolone. If the child becomes steroid dependent then azathioprine should be given for its steroid sparing effect. The duration of such therapy is uncertain but is certainly for several months at the least. Its use in children is now well established. Such a relapse is most likely to occur with colonic disease.

SURGERY

This approach of enteral feeding and drug therapy does not unfortunately prevent the need for surgery in some cases.

Surgical removal of the inflamed bowel can directly stimulate linear growth in children with Crohn's disease who have short stature. ${ }^{27}$ This is particularly striking in those children who are either prepubertal or in early puberty. Then both catch-up growth and the adolescent growth spurt may occur. ${ }^{28}$

\section{Ulcerative colitis}

DIAGNOSIS

The rapid onset of gastrointestinal symptoms, particularly bloody diarrhoea, in most children with ulcerative colitis, tends to result in early referral from the general practitioner and prompt investigation. Most children are diagnosed within six months of their first symptoms.

A provisional diagnosis of ulcerative colitis in children is usually made on the basis of the typical clinical features. However distinction from Crohn's colitis is difficult on clinical grounds alone. The diagnostic approach used for Crohn's disease should be followed.

Definite ulcerative colitis is defined histologically by acute inflammation with severe crypt cell distortion and diffuse goblet cell depletion (mucous depletion). Inflammation is diffuse and solely mucosal. Vascularity is increased.

Probable ulcerative colitis is indicated by:

(1) Diffuse mucosal inflammation with only mild or moderate crypt distortion, mucosal atrophy, or mucous depletion

(2) Diffuse acute and chronic inflammation with increased vascularity but little mucous depletion, suggesting a resolving phase.

MANAGEMENT

Therapy is not so different from adult medicine. ${ }^{29}$

Drugs remain the first line treatment for ulcerative colitis in children. For mild cases oral mesalazine $(20 \mathrm{mg} / \mathrm{kg} /$ day $)$ or sulfasalazine $(50 \mathrm{mg} / \mathrm{kg} /$ day) are recommended. At present sulfasalazine is the only drug available as a suspension for children. When a remission is induced these drugs should continue for two years after the last relapse.

For moderately severe patients treatment with high dose oral steroids in a dose of 1-2 $\mathrm{mg} / \mathrm{kg} /$ day is recommended but never going above the adult dosage. This dose should be continued for 4-6 weeks depending upon the response. It is then tapered over the next three months, at first by daily reductions and then by alternate day reductions. Mesalazine or sulfasalazine should be instituted when treatment is started to maintain a remission. They should be continued for two years as discussed above. When relapse occurs further high dose steroids are indicated. If the child becomes steroid dependent then surgery may be indicated. Recently intravenous azathioprine over five days followed by oral azathioprine has been reported to avoid surgery. ${ }^{30}$

Children with distal disease, that is proctitis, can be difficult to treat. Local steroids as water soluble prednisolone 21 phosphate given dissolved in $20-30 \mathrm{ml}$ of water and given rectally may be successful but rectal 5-ASA derivatives may also be tried.

Severe perineal disease can be the most difficult problem of all. There may be some response to drugs such as metronidazole but therapeutic monoclonals such as Infleximab offer the best hope at present. These drugs are not generally available yet.

Children with ulcerative colitis who present with severe colitis and toxic megacolon are a medical emergency and require urgent treatment with intravenous fluids to correct any fluid and electrolyte disturbances, intravenous antibiotics and intravenous steroids. ${ }^{31}$ There is a risk of perforation in these circumstances and urgent surgical assessment is required. A plain radiograph of the abdomen is immensely valuable and may need to be repeated daily in the sick child. Most children recover medically but some require urgent subtotal colectomy with ileostomy. Surgical treatment is also required when medical management is not satisfactory - for example, steroid dependency with growth slowing or continuing active disease in a child with pancolitis despite therapy. The recommended surgical approach is subtotal colectomy with ileostomy and mucous fistula. ${ }^{32}$

Ileoanal anastomosis with pouch formation is not often done in children with ulcerative colitis but is usually best left until early adult life. However a large study of 73 children in Canada who had this procedure performed in childhood has been reported. ${ }^{33}$ The mean age was 13.2 years with a range of 2.6 to 18.8 years. Unfortunately the anastomosis was nonfunctional in 19 cases (26\%).

\section{Conclusion}

Accurate diagnosis is particularly important in children as management may differ considerably between, for example, Crohn's colitis and ulcerative colitis. Early treatment with effective follow up and tailoring treatment to the child's individual needs is likely to have the best outcome. This should occur in a paediatric gastroenterology unit.

1 Armitage E, Drummond H, Ghosh S, et al. Incidence of juvenile-onset Crohn's disease in Scotland. Lancet 1999;353:1496-7.

2 British Paediatric Association. Tertiary services for children and young people. London: BPA, 1995.

3 Lee JCW, Bridger S, McGregor C, et al. Why children with inflammatory bowel disease are diagnosed at a younger age inflammatory bowel disease are diagnosed at a

4 Beasley SW, Cameron DJS, McLain BI, et al. Diagnostic 4 Beasley SW, Cameron DJS, McLain BI, et al. Diagn
delay in Crohn's disase. Pediatr Surg 1992;7:171-3. 
5 O'Donoghue DP, Dawson AM. Crohn's disease in childhood. Arch Dis Child 1977;52:627-31.

6 Chong SKF, Bartram CI, Campbell CA, et al. Chronic inflammatory bowel disease in childhood. BMF 1982;284: $101-3$.

7 Sanderson IR, Walker-Smith JA. Crohn's disease in childhood. Br f Surg 1985;72(suppl):S87-90.

8 Chong SKF, Blackshaw AJ, Boyle S, et al. Histological diagnosis of chronic inflammatory bowel disease in children. Gu 1985;26:55-9.

9 Domizio P. Pathology of chronic inflammatory bowel disease in children. Baillieres Clin Gastroenterol 1994;8:3563.

10 Bartram CI, Halligan S. Radiological investigation of chronic inflammatory bowel disease in childhood. Baillieres Clin Gastroenterol 1994;8:101-19.

11 Walker-Smith JA. Management of growth failure in Crohn's disease. Arch Dis Child 1996;75:351-4.

12 Brain CE, Savage M. Growth and puberty in chronic inflammatory bowel disease. Baillieres Clinical Gastroenterol 1994;8:83-100.

13 Kirschner BS, Sutton MM. Somatomedin-C levels in growth-impaired children and adolescents with chronic inflammatory bowel disease. Gastroenterology 1986;80:10 15

14 Thomas AG, Holly JM, Taylor C, et al. Insulin-like growth factor-I, insulin-like growth factor binding protein-I, and insulin in childhood Crohn's disease. Gut 1994;34:944-7.

15 Kirschner BS, Klich JR, Kalman SS, et al. Reversal of growth retardation in Crohn's disease with therapy emphasising oral nutritional restitution. Gastroenterology 1981;91: $830-6$.

16 Majrowski WH, Walker-Smith JA, Savage MO. Auxological response to enteral nutrition in childhood Crohn's disease. In: Prader A, Rappaport R, eds. Clinical issues in growth disorders. London: Freund Publishing House, 1994: 19-30.

17 Thomas AG, Taylor F, Miller B. Dietary intake and nutritional treatment in childhood Crohn's disease. $\mathcal{F}$ Pediatr nutritional treatment in childhood

18 Murch SH, Lamkin VA, Savage MO, et al. Serum concentrations of tumour necrosis factor-alpha in childhood
chronic inflammatory bowel disease. Fournal of the British chronic inflammatory bowel disease. Fournal of the British Society of Gastroenterology 1991;8:913-17.

19 Beattie RM, Walker-Smith JA, Murch SH. Indication for investigations of chronic gastrointestinal symptoms. Arch Dis Child 1995;73:354-5.
20 De Benedetti F, Alonzi T, Moretta A, et al. Interleukin 6 causes growth impairment in transgenic mice through decrease in insulin-like growth factor-I. A model for stunted growth in children with chronic inflammation. $\mathcal{F}$ Clin Invest 1997;99:643-50.

21 Breese EJ, Michie CA, Nicholls SW, et al. Effect of treatment on lymphokine-secreting cells in the intestinal mucosa of children with Crohn's disease. Aliment Pharn mucosa of children w

22 Fell JME, Paintin M, Arnaud-Battandier F, et al. Mucosal healing and a fall in mucosal pro-inflammatory cytokine mRNA induced by specific oral polymeric diet in paediatric Crohn's disease. Aliment Pharmacol Ther 2000;14:281-9.

23 Lehrnbecher T, Kontny H-Y, Jeschke K. Metastatic Crohn's disease in a 9 year old boy. $\mathcal{F}$ Pediatr Gastroenterol Nutr 1999; 28:321-3.

24 Walker-Smith JA. Therapy of Crohn's disease in childhood. Baillieres Clin Gastroenterol 1997;11:593-610.

25 Sanderson IR, Udeen S, Davies PSW. Remission induced by an elemental diet in small bowel Crohn's disease. Arch Dis Child 1987;61:123-7.

26 Beattie RM, Schiffrin EJS, Donnet-Hughes A, et al. Polymeric nutrition as the primary therapy in children with small bowel Crohn's disease. Aliment Pharmacol Ther 1994; 8:609-15.

27 Davies G, Evans CM, Shand WS, et al. Surgery for Crohn's disease influence on site of disease and operative procedure on outcome. Br F Surg 1990;77:81-94

28 Evans CM, Kirk JMW, Savage MO, et al. Growth after gut resection for Crohn's disease. Arch Dis Child 1991;66:370.

29 Murch SH, Walker-Smith JA. Medical management of chronic inflammatory bowel disease. Baillieres Clin Gastroenterol 1994;8:133-48.

30 Casson DH, Davies SE, Thomson MA, et al. Low dose intravenous azathioprine may be effective in the management of acute fulminant colitis complicating inflammatory bowel disease. Aliment Pharmacol Ther 1999;13:891-5.

31 Booth IW, Harries JT. Inflammatory bowel disease in childhood. Gut 1984;25:188-202.

32 Shand WS. Surgical therapy of chronic inflammatory bowel disease. Baillieres Clin Gastroenterol 1994;8:149-80.

33 Durno C, Sherman P, Harris K, et al. Outcome of after ileoanal anastomosis in peadiatric patients with ulcerative colitis. F Pediatr Gastroenterol Nutr 1998;27:501-7.

\section{IMAGES IN MEDICINE}

\section{Cutaneous anthrax}

A 20 year old woman grazing goats presented with a five day history of haemorrhagic bullae on her face. The individual lesion started as a small pruritic but painless papule that had enlarged and evolved into the present lesion. She did not have any systemic complaints. The source of infection was traced and found to be infected goats; some of them were dying. Examination revealed three distinct lesions each consisting of haemorrhagic eschar surrounded by small satellite vesicles and brawny non-pitting oedema (see fig 1). Gram staining of a vesicle fluid smear from the cutaneous lesion showed large Gram positive rods suggestive of Bacillus anthracis. Culture from the vesicle fluid confirmed our diagnosis. The differential diagnosis of cutaneous leishmaniasis had been considered but was ruled out on laboratory investigations. The patient was started on crystalline penicillin in the dosage of two million units, intravenously six hourly for 14 days. Complete resolution of the lesion occurred within two weeks.

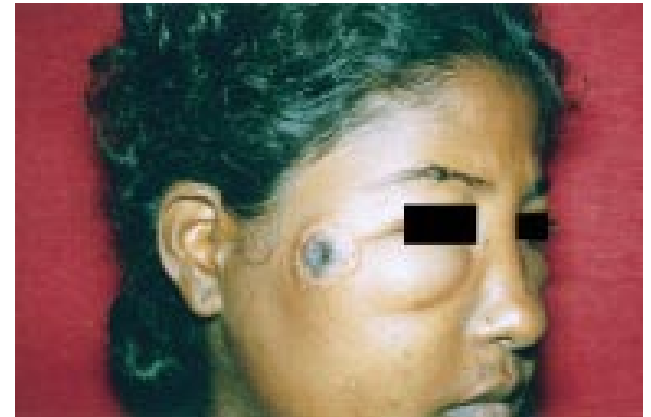

Figure 1 Six day old lesion (reproduced with the patient's permission).

GOMATHY SETHURAMAN DEVINDER M THAPPA KALIAPERUMAL KARTHIKEYAN Department of Dermatology and Sexually Transmitted Diseases,

Fawaharlal Institute of Postgraduate Medical Education and Research (FIPMER), Pondicherry 605 006, India 